\title{
ESCRITA LITERÁRIA MOÇAMBICANA E SABERES ENDÓGENOS
}

\author{
MOZAMBICAN LITERARY WRITING AND \\ ENDOGENOUS KNOWLEDGE
}

Terezinha Taborda Moreira ${ }^{1}$

\section{RESUMO}

Este estudo analisa a construção enunciativa em "As cicatrizes do amor", de Paulina Chiziane (2007), evidenciando como a subjetividade de uma contadora de histórias se enuncia demarcando a presença de uma "gnose africana” (MUDIMBE, 2013) na escrita literária. Procura-se mostrar como a escritora moçambicana, por meio dessa estratégia narrativa, estabelece um comprometimento ético fundamentado na possibilidade de convivência com os saberes endógenos, ou seja, "os saberes e os saberes-fazer da África contemporânea” defendidos por Obarè Bagodo (2014).

PALAVRAS-CHAVE: Escrita literária; saberes tradicionais; Paulina Chiziane.

\section{ABSTRACT}

This study analyzes the enunciative construction in the short story "As cicatrizes do amor", by Paulina Chiziane (2007), exploring how the subjectivity of a storyteller enunciates itself demarcating the presence of an "African gnosis" (MUDIMBE, 2013) in the literary writing. The text seeks to show how the writer, by this narrative strategy, establishes an ethical commitment reasoned in the possibility of coexistence with the endogenous knowledge, thus, "the knowledges and know-how of contemporary Africa" defended by Obare Bagodo. (2014).

KEYWORDS: Literary writing; traditional knowledge; Paulina Chiziane. 
Este estudo aborda o conto "As cicatrizes do amor", da escritora moçambicana Paulina Chiziane (2007), como uma representação estética na qual tanto a construção discursiva quanto a configuração dos sujeitos ficcionais evidenciam a presença, na tessitura narrativa, de uma "gnose africana" (MUDIMBE, 2013, p. 9) que remete às condições sócio-históricas que originam a escrita literária mesma, ao mesmo tempo em que ilumina a reflexão sobre os contextos epistemológicos nos quais ela se fundamenta.

O conto narra a história de Maria, filha do régulo de Matutuíne, que tem sua mão negada a um homem pobre, por este não ter condições de lobolar a filha do rei. Ultrajado, o homem segue para Johannesburg para o trabalho nas minas, enquanto Maria dá à luz uma menina. Expulsa de casa, Maria inicia uma saga em busca do amado, pai de sua filha. Saga porque, em seu percurso, aquilo que ela acaba construindo é a sua própria liberdade na sociedade patriarcal e tradicional em que vive. O conto é narrado a partir do presente, por uma narradora-personagem que frequenta a caserna de Maria, espécie de zona neutra onde valores da tradição cultural moçambicana convivem com valores da sociedade capitalista contemporânea, adquiridos a partir da colonização, das guerras pela independência e civil, enfim, de eventos históricos que definem o multiculturalismo na pós-independência moçambicana.

O tom poético na descrição de personagens e lugar marca a abertura da narrativa. E já em seu início chama nossa atenção a maneira como se organiza a enunciação: a subjetividade que emerge no relato se apresenta como um "eu" que se dirige a um "outro" ora ressaltando sua individualidade, ora permitindo que sua individualidade se dilua num coletivo que lhes remete, a ambos, para um universo cultural moçambicano encenado como um espaço plural e aberto à participação de um grupo que partilha uma experiência comum:

Diabos me levem se não estou bem nesta rodada de mulheres sentadas na areia e os homens nas cadeiras. Todas as gargantas regam-se na fonte do uputo que flui aos borbotões. $\mathrm{O}$ ambiente confortável é de gente humilde, sincera, andrajosa e descalça.

A brisa suleste brinca no chapéu dos cajueiros. Os corpos exsudados pelo verão deliram com os beijos das brisas. $\mathrm{O}$ céu nublado transfere o cinzento feio para a transparência do Índico. Corvos em revoada grasnam agouros que ninguém liga. Quem entra na caserna de Maria bebe alegrias e esquece o resto. É verdade, sim. Neste campo de deslocados na Inhaca, o povo triste recria felicidade.

Uma mosca bailando ao vento despista-se, cai no meu copo e debate-se louca. Que azar!

- Que sorte! A mosca dá sorte, menina!

Sorte? Sorte, sim senhora, confirmam os sorrisos. Com a ponta da unha removi a intrusa, vazei o copo num trago, não ia a sorte volatilizar-se. 
Semicerrei as pálpebras sorvendo a delícia daquele paraíso de miséria. O uputo é bom e a bebida fresca: a música é dos pássaros e o calor dos sorrisos. As mãos de todos espalmam-se em apertos vigorosos, frenéticos, com saudações de boas-vindas, compadre, vai um copo, não vai? (CHIZIANE, 2007, p. 361-362).

O início da leitura nos coloca, assim, diante de uma subjetividade que se elabora reconstruindo a ambientação coletiva da "rodada de mulheres sentadas na areia" e de "homens nas cadeiras" da caserna de Maria. Com esse modo de enunciação, a subjetividade emerge no relato ultrapassando a mera interação verbal para propor, com o leitor, uma aproximação na qual investe língua, crenças, modos de ser, saberes, psicologia, enfim.

Por isso o leitor perceberá que, no espaço multicultural em que se constitui a caserna de Maria, o comportamento cultural tradicional que legitima que mulheres se sentem na areia enquanto homens se sentem nas cadeiras convive com um comportamento contemporâneo, pelo qual a confraternização aproxima todos à "fonte do uputo que flui aos borbotões". Perceberá também que, na caserna de Maria, o confronto entre colonização e pós-colonialidade, ou pós-independência, institui a condição de "deslocados na Inhaca" que caracteriza a "gente humilde, sincera, andrajosa e descalça" que, juntamente com a subjetividade que enuncia essa gente e a si mesma, "recria felicidade". Perceberá, ainda, a condição de entrelugar assumida pela subjetividade que se constitui no relato. Entrelugar porque, por um lado, ela confessa não dominar alguns valores da cultura tradicional daquele grupo de "deslocados" junto ao qual ela se encontra, como a sorte que a mosca traz ao cair no copo de uputo. Porém, por outro lado, ela se assume como articuladora de um discurso que somente se realiza pelo entrecruzamento dos saberes dessa mesma cultura tradicional com a representação escrita a partir da qual se organiza o relato.

A noção de entrelugar está sendo pensada aqui a partir das reflexões de Homi K. Bhaha, para quem o entrelugar é um local intersticial, que, por isso mesmo, fornece "terreno para a elaboração de estratégias de subjetivação - singular ou coletiva - que dão início a novos signos de identidade e postos inovadores de colaboração e contestação, no ato de definir a própria ideia de sociedade." (BHABHA, 1998, p. 21). A reflexão de Bhabha nos auxilia a compreender como, na narrativa de Paulina Chiziane, a enunciação se articula como espaço intersticial que permite a constituição de uma subjetividade que se constrói fora das ideias de unificação e fixação em polos tradicionais que sempre orientou a construção das identidades. Assim, ao assumir o espaço de expressão da voz - a escrita - como um entrelugar, a subjetividade se constrói falando de si e do outro ao mesmo tempo, ambos remetidos para uma experiência comum. Para fazê-lo, propõe uma enunciação que aceita a escrita como espaço de expressão, mas organiza o dizer a partir de uma lógica que recupera a performance oral típica dos(as) contadores(as) de histórias da cultura moçambicana. Ou seja, 
a enunciação narrativa se articula pela emergência, na escrita literária, de uma subjetividade que se institui como contadora de histórias.

Como contadora de histórias, a narradora adota uma perspectiva deslizante, que ora gera um eu interno à narrativa, que vive os acontecimentos descritos como testemunha ${ }^{2}$ ("Diabos me levem se não estou bem nesta rodada de mulheres sentadas na areia e os homens nas cadeiras...”); ora propicia o surgimento de uma percepção onisciente neutra que se insinua em terceira pessoa ("A brisa suleste brinca no chapéu dos cajueiros. Os corpos exsudados pelo verão deliram com os beijos das brisas. O céu nublado transfere o cinzento feito para a transparência do Índico. Corvos em revoada grasnam agouros que ninguém liga"); ora assume a postura de uma autora onisciente intrusa, que emite suas opiniões sobre os acontecimentos ("Quem entra na caserna de Maria, bebe alegrias e esquece o resto. É verdade, sim. Neste campo de deslocados na Inhaca, o povo triste recria felicidade").

O deslizamento da focalização resulta da maneira como a enunciadora organiza o relato, dividindo, com a personagem Maria, a centralidade da narrativa. Assim, as histórias da narradora e da personagem Maria são enunciadas em relação paralelística. Tal construção permite à narradora criar duas imagens contrapontuais de Moçambique: a de Maria, remetendo ao passado tradicional, colonial, e a de sua subjetividade de contadora de histórias, localizando-se na contemporaneidade moçambicana, pós-independente. A criação de duas imagens contrapontuais da realidade moçambicana permite à narradora propor a seu leitor-espectador uma experiência reflexiva sobre o país.

A apresentação da narrativa por meio de duas histórias contrapontuais evidencia algo como um modo protocolar de organização do dizer representativo dos saberes endógenos que caracterizam a performance oral das narrativas na cultura moçambicana. Trata-se de uma maneira singular de instalar a narração a partir de citações da textualidade oral - provérbios, mitos, adivinhas, ditos populares, etc. - que funcionam de maneira a espelhar o relato como um todo, projetando-se sobre ele para definir o tema e o desenrolar dos acontecimentos. O relato responde a uma intenção do narrador, o contador de histórias, de propor uma reflexão para o grupo ao qual se direciona. Portanto, a partir de uma retomada de elementos do imaginário mítico, histórico e social local, em função de uma proposta reflexiva, o narrador oral projetaria, sobre a narrativa vindoura, a experiência passada, a qual deveria servir-lhe de suporte.

Harold Scheub (1970; 1971; 1972 e 1977), estudando a performance oral das comunidades bantu3, defende a ideia de que o performer trabalha com uma comunidade que tem o mesmo repertório de imagens que ele tem, propiciando a realização de uma experiência comum. Por serem as imagens de domínio público, os membros da comunidade não têm, com elas e para elas, uma experiência e uma história únicas. Mas as dife- 
rentes histórias e experiências são necessárias, pois a performance exige tanto diversidade quanto similaridade de emoções para surtir o seu efeito de atrair a audiência que dela participa. O sistema narrativo oral se torna, portanto, um complexo entretecimento de modelos de imagens produtoras de mensagens, cujo objetivo é proporcionar uma experiência comum.

A partir das reflexões de Scheub podemos pensar que, ao contar, a voz do narrador oral, num movimento espiralar, agenciaria o relato explicitando o motivo pelo qual conta sua história e, ao mesmo tempo, referenciando a força de permanência do passado e a capacidade do mesmo de influenciar o futuro. Esse saber endógeno orienta a narrativa de Paulina Chiziane. Nela a apresentação paralelística e contrapontual das histórias da narradora e de Maria denunciará os desígnios que levam as personagens a agir, seja no passado ou no presente moçambicano. Ao mesmo tempo, essa mesma organização enunciativa convidará o leitor a refletir criticamente sobre esses desígnios e, consequentemente, sobre a realidade social e cultural de Moçambique. É o que vemos na seguinte passagem:

Alguém folheia um jornal velho.

- Veja isto, compadre. Duas crianças abandonadas pelas mães.

A dona de casa deixa de farfalhar, estampa olhos no jornal machucado tentando identificar os rostinhos dos infelizes.

- O que lhes aconteceu?

- Alguém as deitou fora. As mulheres estão doidas.

- São os efeitos do PRE - respondeu o outro. - Se os pais comprarem o leite para os meninos, não sobra nada para os copos. Não há dúvida. A maldade grassa nos dias que passam.

- A maldade nasceu antes da humanidade. A culpa cabe às mães mas é de toda a sociedade - sentenciou a mulher.

- Não fuja da verdade, comadre, que a culpa está com as mulheres. O que dizes é suruma da bebedeira, estás embriagada, sim.

A voz de limão do homem duro era palha seca na fogueira tosca.

- O que vocês não sabem - disse Maria - é que cada nascimento tem uma história e cada acção, uma razão. Na minha juventude cometi o mesmo crime, ou melhor, ia cometê-lo. Tudo por causa desse amor amargura, amor escravatura, que transtorna, que enfeitiça, fazendo do amante a sombra do amado.

Maria entristece. Ergue os olhos para o céu na súplica do silêncio. A mente recua na trajectória distante, mais veloz que a estrela cadente. Baixa os olhos para a terra infértil, salpicada de ervas tisnadas. (CHIZIANE, 2007, p. 362-363).

O episódio narrado coloca em evidência uma realidade vivenciada pelo grupo de deslocados da Inhaca que partilha experiências comuns na caserna de Maria. A notícia de duas crianças abandonadas pelas 
mães parece despertar os presentes do "paraíso de miséria" da "fonte de uputo" em que se encontram para as intempéries vivenciadas em função das guerras pela independência e civil, das diferenças étnicas e de classe, entre outras, que colocam todos na condição de deslocados. Na especulação sobre os motivos do abandono, a "voz de limão do homem duro" que culpa as mães pelo destino das crianças desperta, na personagem Maria, um questionamento profundo sobre a sociedade moçambicana, à qual ela responsabiliza pelos infortúnios impostos à população. Para apresentar seu questionamento, a personagem, então, assume o protagonismo de sua própria narrativa e conta sua história. Esta, remetendo ao passado de Maria, se erige como contraponto à história de abandono veiculada pelo jornal que, até então, vinha sendo contada pela narradora no presente da narrativa:

Lembro-me da noite sem lua, quando debaixo do cajueiro disse sim ao homem dos meus sonhos. O régulo de Matutuíne, meu pai, disse não a esse pobre, sem gado para lobolar a filha do rei. Ao meu homem ultrajado não restou outra alternativa senão procurar o lenitivo das mágoas do outro lado da fronteira, em Johannesburg, deixando-me o ventre semeado. Nos nove meses de gesta, minha alma em suplício consumiu facadas. Quinze dias depois do nascimento da criança, o meu pai disse: fora desta casa. [...]

Supliquei clemência à humanidade: recorri à amizade. Em vão. A amizade abraça a riqueza que é beleza, e não a tristeza que é leprosa. Amor verdadeiro só a terra dá, quando no fim da jornada ela diz: repousa nos meus braços por toda a eternidade. (CHIZIANE, 2007, p. 363)

Para Scheub, entre outros (SCHEUB, 1970; 1971; 1972; 1977; FINNEGAN, 1976, 1977; ZUMTHOR, 1997), na performance narrativa oral, uma habilidade que se espera do performer é a de evocar imagens do mundo contemporâneo e imagens que pertencem ao repertório artístico da tradição oral e inseri-las num sistema paralelístico no qual elas vão misturar-se e, consequentemente, gerar uma atemporalidade narrativa a partir da ruptura com a relação entre passado, presente e futuro. Como dissemos acima, o performer trabalha com um repertório de imagens que partilha com a comunidade à qual pertence. Por isso mesmo, o que provoca a expectativa em sua audiência é a forma como ele vai alterar as imagens que evoca em sua performance e, a partir dessa alteração, como ele vai propiciar à audiência uma experiência reflexiva comum.

No entrecruzamento de vozes que estrutura a narrativa de Maria, a enunciação se abre com uma série de provérbios, o que instala um movimento projetivo do passado sobre o futuro na articulação do dizer. A saga de Maria é determinada pelo passado mítico projetado pelos provérbios. O primeiro provérbio espelha a trajetória sofrida da, agora, narradora-personagem Maria. Nesse caso, a voz oracular da tradição configura o perfil de uma heroína com um destino já traçado: "Supliquei clemência à humanidade; recorri à amizade. Em vão.” (CHIZIANE, 2007, p. 363). E o 
segundo provérbio, voltado inteiramente para o futuro, confirma o destino previsto e sentencia o seu cumprimento, embora a personagem vá lutar, incessantemente, para revertê-lo: "Amarrei a capulana bem firme; com o bebé bem seguro nas costas, jurei: os empecilhos que obstam a minha estrada serão removidos pela minha mão. Chegarei a Johannesburg, minha terra de promissão". (CHIZIANE, 2007, p. 363). A partir daí, todo o percurso da personagem, inclusive no momento em que narra sua história, colocar-nos-á diante de uma mulher perseverando sempre para sobreviver à tradição cultural que lhe traçara um destino de abandono.

Citados, ambos os provérbios endossam a voz oracular, já que a saga da heroína se cumpre como espelhamento do destino projetado pelo microdiscurso proverbial, ao mesmo tempo em que remete, de volta e também por um efeito de espelhamento, a cada um dos provérbios. Assim é que a predestinação de Maria a submeterá à saída da casa dos pais ainda pela madrugada para caminhar, dias e noites, em direção ao Cruzeiro do Sul; ao medo e à solidão por sair de uma área rural para atravessar um país e adentrar um espaço estranho; ao enfraquecimento da criança, cujo corpinho frágil quase sucumbe à viagem; à falta de solidariedade com que ela se depara; a condições degradantes de trabalho escravo; à revolta; à transgressão.

Os provérbios dinamizam a narrativa, projetando os eventos passados sobre a saga de Maria a qual acompanhamos ao longo do relato. Eles assumem, então, o caráter de enunciação de um destino de destruição, sofrimento, traição, humilhação, ódio, ameaça de morte, entre outros, o qual vai ser atualizado na saga de Maria. Inseridos na cadeia linear dos acontecimentos, os provérbios não a rompem. Porém, eles estancam o discurso, fixam-no e instauram, no próprio discurso de Maria, um outro jogo de espelhamento. Esse novo jogo de espelhamento proposto na enunciação narrativa remeteria à estrutura espiralar por meio da qual passado, presente e futuro se encontram numa enunciação curvilínea, cuja circularidade já fora anunciada pela narradora mesma, quando, no início da história, instalara a narração na rodada de mulheres sentadas na areia e de homens sentados nas cadeiras, a qual se configura como um microcosmo que encena as várias espacialidades que conformam o país.

Assim, ao citá-los, a narradora-personagem Maria se apropria do saber endógeno dos provérbios. Porém, ela não adota uma atitude passiva em relação ao sentido que eles, como também a tradição que representam, projetam sobre sua vida. Ao contrário, ela o subverte e, por meio dessa subversão, ressignifica a própria vida. A partir de então, sua saga projetará, sobre a narrativa do presente, um novo significado para as ações das mulheres na sociedade, que gerará a reflexão crítica pretendida ao se construir a narrativa como jogo de espelhamento do passado sobre o presente. A expectativa de Maria é que a audição de sua história faça com que os presentes reflitam sobre o presente e sobre as causas do abandono das crianças. E parece ser esta, também, a expectativa da narradora, quando projeta não apenas sobre o presente moçambicano, mas do mundo, a narrativa pregressa de Maria: 
Retalhos da vida, revolteando as entranhas de quem as escuta. Atenção! O que aqui se conta, está a acontecer agora!, em qualquer parte do mundo. E tu bailas, Maria, o streep-tease das batucadas da tua amargura, que a embriaguez revolveu-te a língua. Desatas o lenço e a capulana. Da blusa já levantada, espreitam os seios surrados de mil beijos, desfraldas as cortinas dos teus segredos, és indecente, Maria! (CHIZIANE, 2007, p. 364).

Ao instituir a enunciação por meio do jogo de espelhamentos, a narradora agencia o relato explicitando o motivo pelo qual conta sua história e, ao mesmo tempo, reverenciando a força de permanência do passado e a capacidade do mesmo de influenciar o futuro. Isso se evidencia nas observações que faz sobre a reação dos presentes à exposição de Maria: "Eu, pecador me confesso. Sorvi a taça do abominável, fluindo da garganta da autora. Com o simples relancear da vista tentei penetrar no secreto de cada alma. Afinal quem somos nós? Em quantos vendavais nos espiralamos até galgar o degrau do presente?” (CHIZIANE, 2007, p. 366). Tais observações mostram que se alcançou o propósito pretendido de promover a reflexão, já que, ao longo da narrativa de Maria os presentes, "hipnotizados pela tua [de Maria] dor" (CHIZIANE, 2007, p. 365), silenciam diante do desnudamento das verdades íntimas e sagradas que determinam o comportamento da mulher, cúmplices agora contra a sociedade que a conduziu aos caminhos da tragédia:

Porque escondes os olhos, Maria? Talvez te envergonhes dos teus actos, talvez te arrependas do teu relato, ou mesmo te revoltas contra a sociedade que te conduziu aos caminhos da tragédia. As cicatrizes do amor rasgaram as crostas e jorraram um líquido sangue que escorre pelas curvas das tuas pálpebras. (CHIZIANE, 2007, p. 367).

Para Harold Scheub $(1970 ; 1971 ; 1972 ; 1977)$, o performer trabalha com experiências idiossincráticas, esforçando-se por amalgamá-las; embora sem eliminar as suas diferenças, esforça-se por unificá-las em uma experiência comum. Assim, o sistema narrativo se torna um complexo entretecimento de modelos e imagens que produzem mensagens cujo objetivo seria o de proporcionar uma vivência partilhável. O resultado dessa composição estrutural seria a tendência a priorizar o efeito temático sobre a composição psicológica das personagens, atualizando-se, assim, modos de ser e de estar próprios da cultura em variados contextos temporais.

Essa organização estrutural se inscreve na narrativa de Paulina Chiziane pela contraposição de imagens do passado da personagem Maria e imagens do presente na caserna. Contrapostas, essas imagens desenham-nos um mesmo cenário, marcado pela tradição do lobolo, pela tradição da mulher cuidando da educação dos filhos, pelo trabalho nas minas de Johannesburg, pela peregrinação de exilados e deslocados de guerra, pelo caos político e social que gera a fome e as desigualdades sociais, pela sub- 
missão da mulher ao amor e, ao mesmo tempo, pela força transformadora em que ela se constitui. Cada imagem se refere ao passado, ao presente ou a ambos, simultaneamente. Elas respondem a um enquadramento das personagens em suas relações umas com as outras, com a sociedade, com as circunstâncias sociais, econômicas, políticas e históricas nas quais todos os presentes estão mergulhados.

Acreditamos que, ao adotar essa organização estrutural em sua narrativa, a escritora Paulina Chiziane propõe um outro modo de relacionamento entre a escrita literária e a realidade. Esse modo de relacionamento é indicado pela escritora mesma, em uma afirmação relativa a seu processo de escrita, feita na contracapa de seu romance Niketche: uma história de poligamia (2002):

\begin{abstract}
Dizem que sou romancista e que fui a primeira mulher moçambicana a escrever um romance (Balada de amor ao vento, 1990), mas eu afirmo: sou contadora de estórias e não romancista. Escrevo livros com muitas estórias, estórias grandes e pequenas. Inspiro-me nos contos à volta da fogueira, minha primeira escola de arte. (CHIZIANE, 2002).
\end{abstract}

A nosso ver, a identificação de si mesma como uma contadora de história deve ser lida como uma referência da escritora a como ela se posiciona em relação à literatura e ao fazer literário demarcando seu lugar de fala, também, em uma gnose africana. Nesse sentido, ela reivindicaria, para a escrita literária, um comprometimento ético cujo fundamento estaria na possibilidade de sua convivência com os saberes endógenos, ou seja, "os saberes e os saberes-fazer da África contemporânea" (BAGODO, 2014, p. 53), constituídos há séculos, mas passíveis de processos de atualização, automodernização e reciclagens próprias e dinâmicas, de acordo com o tempo e o espaço em que se inserem. Saberes e saberes-fazer cuja "modernidade científica”, dizendo com Obarè Bagodo (2014, p. 53), se poderia verificar no uso que dela se faz e no julgamento de valor que poderia decorrer desse uso. Como vemos em sua narrativa "As cicatrizes do amor".

\title{
REFERÊNCIAS BIBLIOGRÁFICAS
}

BAGODO, Obarè. Saberes endógenos e desafios da modernidade científica: reflexões de um arqueólogo. In: HOUNTONDJI, Paulin J. (Org.) $O$ antigo e o moderno. A produção do saber na África contemporânea. Mangualde; Luanda: Edições Pedago; Edições Mulemba, 2014.

BHABHA, H. K. O local da cultura. Trad. Myriam Ávila et al. Belo Horizonte: UFMG, 1998.

CHIZIANE, Paulina. As cicatrizes do amor. In: SAÚTE, Nelson (Org.) As mãos dos pretos. Antologia do conto moçambicano. Lisboa: Publicações Dom Quixote. 3. ed. 2007, pp. 361-367. 
. Niketche: uma história de poligamia. 3. ed. Lisboa: Editorial Caminho, 2002.

FINNEGAN, Ruth. Oral literature in Africa. Oxford: University Press, 1976.

Oral poetry: its nature, significance and social context. Cambridge University Press, 1977.

HOUNTONDJI, Paulin J. Conhecimento de África, conhecimento de africanos: duas perspectivas sobre os estudos africanos. In: SANTOS, Boaventura de Sousa; MENESES, Maria Paula (Orgs.) Epistemologias do Sul. Coimbra: Edições Almedina, 2009, p. 119-131.

LEITE, Ligia Chiappini Moraes. O foco narrativo. São Paulo: Ática, 1985.

MUDIMBE, Valentin Yves. A invenção de África: gnose, filosofia e a ordem do conhecimento. Mangualde (Portugal), Luanda: Edições Pedago; Edições Mulemba, 2013.

SCHEUB, Harold. Translation of african oral narrative-performances to the written word. Yearbook of Comparative and General Literature, v. 20, 1971, p. 28-36.

. Fixed and nonfixed symbols in Xhosa and Zulu oral narrative traditions. Journal of American Folklore, v. 85, n. 337, jul./sept. 1972, p. 268-273.

. Oral narrative process and the use of models. New Literatry History: A Journal of theory \& Interpretation, v. 6, 1975, p. 353-377.

. Body and image in oral narrative performance. New Literatry History: A Journal of theory \& Interpretation, v. 8, 1976-1977, p. 345-368.

. Performance of oral narrative. In: BASCOM, William R. (Ed.). Frontiers of folklore. USA: Westview Press, 1977, p. 54-78.

. Oral poetry and history. New Literatry History: A Journal of theory \& Interpretation, v. 18, 1986-1987, p. 178-196.

SERRA, Carlos (Org.). História de Moçambique, v. I [Primeiras sociedades sedentárias e impacto dos mercadores: 200/300-1986]. Maputo: Departamento de História da Universidade Eduardo Mondlane, 1988.

. História de Moçambique, v. III [Moçambique no auge do colonialismo: 1930-1961]. Maputo: Departamento de História da Universidade Eduardo Mondlane, 1993.

ZUMTHOR, Paul. A encruzilhada dos rhétoriqueurs: intertextualidade e retórica. In: Poetique: Revue de Théorie et d'Analyse Littéraires, Coimbra, n. 27, 1979, p. 109-146. 
. A letra e a voz: a "literatura" medieval. Trad. Amálio Pinheiro e Jerusa Pires Ferreira. São Paulo: Companhia das Letras, 1993.

. Introdução à poesia oral. Trad. Jerusa Pires Ferreira. São Pau-

lo: Hucitec, 1997.

Recebido para publicação em 30/10/2016

Aprovado em 03/11/2016

\section{NOTAS}

1 Pontifícia Universidade Católica de Minas Gerais. Belo Horizonte. Professora Adjunta da PUC Minas. Pesquisadora CNPq-Nível 2. Este trabalho é parte das reflexões desenvolvidas no âmbito do Grupo de Pesquisa “África e Brasil: repertórios literários e culturais" e tem o apoio do CNPq.

2 Ao longo deste estudo são utilizadas algumas das referências criadas por Norman Friedman para a classificação do narrador, como as de testemunha, autor onisciente intruso e narrador onisciente. (Cf. LEITE, 1985).

3 "A palavra bantu tem uma conotação exclusivamente linguística e surgiu em 1862, sob proposta do linguista alemão Bleek, para assinalar o grande parentesco de cerca de 300 línguas, as quais utilizavam todas esse vocábulo para designar 'os homens' (singular muntu). Não existe, portanto, uma raça Bantu.” (SERRA, 1988, p. 49). 